\title{
Kidney-synthesized erythropoietin is the main source for the hypoxia-induced increase in plasma erythropoietin in adult humans
}

\author{
Lundby, Anne-Kristine Meinild ; Keiser, Stefanie ; Siebenmann, Christoph ; Schäffer, Leonhard ; \\ Lundby, Carsten
}

\begin{abstract}
PURPOSE Erythropoietin (EPO) is mainly synthesized within renal peritubular fibroblasts, and also other tissues such as the liver possess the ability. However, to what extent non-kidney produced EPO contributes to the hypoxia-induced increase in circulating EPO in adult humans remains unclear. METHODS We aimed to quantify this by assessing the distribution of EPO glycoforms which are characterized by posttranslational glycosylation patterns specific to the synthesizing cell. The analysis was performed on samples obtained in seven healthy volunteers before, during and after 1 month of sojourn at 3,454 m altitude. RESULTS Umbilical cord (UC) plasma served as control. As expected a peak ( $p<$ $0.05)$ in urine $(2.3 \pm 0.5$-fold) and plasma (3.3 \pm 0.5 -fold) EPO was observed on day 1 of high-altitude exposure, and thereafter the concentration decreased for the urine sample obtained after 26 days at altitude, but remained elevated $(\mathrm{p}<0.05)$ by $1.5 \pm 0.2$-fold above the initial sea level value for the plasma sample. The EPO glycoform heterogeneity, in the urine samples collected at altitude, did not differ from values at sea level, but were markedly lower $(\mathrm{p}<0.05)$ than the mean percent migrated isoform $(\mathrm{PMI})$ for the umbilical cord samples. CONCLUSION Our studies demonstrate (1) UC samples express a different glycoform distribution as compared to adult humans and hence illustrates the ability to synthesis EPO in non-kidney cells during fetal development (2) as expected hypoxia augments circulating EPO in adults and the predominant source here for remains being kidney derived.
\end{abstract}

DOI: https://doi.org/10.1007/s00421-014-2844-7

Posted at the Zurich Open Repository and Archive, University of Zurich

ZORA URL: https://doi.org/10.5167/uzh-109680

Journal Article

Published Version

Originally published at:

Lundby, Anne-Kristine Meinild; Keiser, Stefanie; Siebenmann, Christoph; Schäffer, Leonhard; Lundby, Carsten (2014). Kidney-synthesized erythropoietin is the main source for the hypoxia-induced increase in plasma erythropoietin in adult humans. European Journal of Applied Physiology, 114(6):1107-1111. DOI: https://doi.org/10.1007/s00421-014-2844-7 


\title{
Kidney-synthesized erythropoietin is the main source for the hypoxia-induced increase in plasma erythropoietin in adult humans
}

\author{
Anne-Kristine Meinild Lundby • Stefanie Keiser • \\ Christoph Siebenmann $\cdot$ Leonhard Schäffer · \\ Carsten Lundby
}

Received: 17 October 2013 / Accepted: 3 February 2014 / Published online: 15 February 2014

(C) Springer-Verlag Berlin Heidelberg 2014

\begin{abstract}
Purpose Erythropoietin (EPO) is mainly synthesized within renal peritubular fibroblasts, and also other tissues such as the liver possess the ability. However, to what extent non-kidney produced EPO contributes to the hypoxia-induced increase in circulating EPO in adult humans remains unclear.

Methods We aimed to quantify this by assessing the distribution of EPO glycoforms which are characterized by posttranslational glycosylation patterns specific to the synthesizing cell. The analysis was performed on samples obtained in seven healthy volunteers before, during and after 1 month of sojourn at 3,454 m altitude.

Results Umbilical cord (UC) plasma served as control. As expected a peak $(p<0.05)$ in urine $(2.3 \pm 0.5$-fold $)$ and plasma ( $3.3 \pm 0.5$-fold) EPO was observed on day 1 of high-altitude exposure, and thereafter the concentration decreased for the urine sample obtained after 26 days at altitude, but remained elevated $(p<0.05)$ by $1.5 \pm 0.2-$ fold above the initial sea level value for the plasma sample. The EPO glycoform heterogeneity, in the urine samples
\end{abstract}

Communicated by Guido Ferretti.

A.-K. M. Lundby $\cdot$ S. Keiser · C. Siebenmann $\cdot$ C. Lundby $(\bowtie)$ Center for Integrative Human Physiology, Institute of Physiology, University of Zürich, Winterthurerstrasse 190, 8057, Zürich, Switzerland

e-mail: carsten.lundby@access.uzh.ch

L. Schäffer

Department of Obstetrics, University Hospital Zürich, Zürich, Switzerland

C. Lundby

Food and Nutrition and Sport Science, Gothenburg University, Gothenburg, Sweden collected at altitude, did not differ from values at sea level, but were markedly lower $(p<0.05)$ than the mean percent migrated isoform (PMI) for the umbilical cord samples.

Conclusion Our studies demonstrate (1) UC samples express a different glycoform distribution as compared to adult humans and hence illustrates the ability to synthesis EPO in non-kidney cells during fetal development (2) as expected hypoxia augments circulating EPO in adults and the predominant source here for remains being kidney derived.

Keywords $\mathrm{EPO} \cdot \mathrm{Renal} \cdot$ Altitude

$\begin{array}{ll}\text { Abbreviations } \\ \text { EPO } & \text { Erythropoietin } \\ \text { Glc-NAc } & N \text {-acetylglucosamine } \\ \text { HA } & \text { High altitude } \\ \text { MAIIA } & \text { Membrane-assisted isoform immunoassay } \\ \text { PMI } & \text { Percent migrated isoform } \\ \text { SL } & \text { Sea level } \\ \text { WGA } & \text { Wheat germ agglutinin } \\ \text { UC } & \text { Umbilical cord }\end{array}$

\section{Introduction}

Erythropoietin (EPO) governs hemoglobin concentration and thus arterial oxygen content by regulating red blood cell and plasma volumes (Jelkmann 1992; Lundby et al. 2007; Olsen et al. 2011). The classic view is that hypoxia stimulates the synthesis and release of EPO in renal peritubular fibroblasts. Work based on HIF-1 knock-out mice however suggested that astrocytes, which express both EPO and its receptor (Bernaudin et al. 2000), may contribute by as much as $50 \%$ to the hypoxia-induced increase in plasma 
EPO (Weidemann et al. 2009). In divergence hereto we observed no detectable release of EPO from the hypoxic human brain to the blood stream or to cerebral spinal fluid (Rasmussen et al. 2012). In contrast to the HIF-1 knockout study, however, the samples were obtained after 4 and $8 \mathrm{~h}$ of hypoxic exposure when the erythropoietic response to hypoxia may not yet have reached its peak, which is usually reached within the first 1-3 days of exposure (Robach et al. 2007).

Besides astrocytes (Masuda et al. 1994) EPO may also be synthesized in the liver and based on EPO mRNA analysis it is generally accepted that this is the main site for EPO production during gestation (Dame et al. 1998; Ohls 2002). Adult rodent liver retains its ability to produce EPO in response to hypoxia or HIF activation (Fried 1972; Kapitsinou et al. 2010; Minamishima and Kaelin 2010). Other cells have also been demonstrated to be capable of synthesizing EPO although only in minor quantities (Haase 2010) and accordingly nephrectomized humans demonstrate elevated EPO levels (Mirand et al. 1968). However, to what extent these non-renal EPO production sites contribute to the hypoxia-induced increase in plasma EPO in adult humans remains elusive. Since the posttranslational glycosylation patterns of the different EPO glycoforms are specific to their synthesizing cells (Lönnberg et al. 2013; Masuda et al. 1994; Wide and Bengtsson 1990), the contribution of the various synthesizing cells to the circulating EPO concentration can be determined by analysis hereof. In the present study, we analyzed EPO glycoform composition of healthy humans exposed to altitude for 1 month and thereby evaluated the contribution of EPO originating from non-kidney cells to the hypoxia-dependent increase in circulating EPO. As control we used EPO purified from umbilical cord (UC) samples since the glycosylation pattern observed here most likely differentiates from that seen in adults (Wide and Bengtsson 1990). Based on our previous study conducted in acute hypoxia (Rasmussen et al. 2012), we hypothesized that EPO originating from the kidney will remain the main source for circulating EPO in hypoxic adult humans.

\section{Methods}

Seven healthy male sea-level dwellers with no exposure to altitudes above 2,000 $\mathrm{m}$ for the last 4 weeks ( $26 \pm 4$ years; $180 \pm 1 \mathrm{~cm} ; 76 \pm 6 \mathrm{~kg}$ ) participated in this study which was approved by the Ethical Committee for the Eidgenössische Technische Hochschule Zürich (EK 2011-N-51) and conducted in accordance with the declaration of Helsinki. Prior to the start of the experiments, informed oral and written consents were obtained. After baseline sampling in Zürich $(480 \mathrm{~m})$ all subjects were transported by train to the Jungfraujoch Research Station (3,454 m, Bernese Alps, Switzerland) where they stayed for 4 consecutive weeks. The facilities provide normal living conditions, comfortable room temperatures and access to food as consumed at sea level.

Urine and venous plasma samples were collected from all subjects at sea level (SL), and then after 1 (HA1; $17 \pm 1 \mathrm{~h}$ ), 3 (HA3; $65 \pm 1 \mathrm{~h}$ ) and 26 (HA26) days of altitude exposure, and again after $7(\mathrm{SL}+7)$ and $14(\mathrm{SL}+14)$ days upon return to sea level. All samples were stored at $-80{ }^{\circ} \mathrm{C}$.

Total plasma EPO concentrations were determined by means of a solid-phase sandwich ELISA kit and concentrations were determined based on the standard provided with the kit (Human Erythropoietin Quantikine IVD ELISA Kit, Quantikine, R\&D Systems, Minneapolis, USA). Total urine EPO concentrations were determined by membraneassisted isoform immunoassay (MAIIA) (EPO Quantification Urine Kit, MAIIA Diagnostics, Uppsala, Sweden) as specified by the manufacturer. In short, $0.5 \mathrm{ml}$ of each urine sample was desalted and the EPO concentration determined by lateral flow immunoassay (Lönnberg et al. 2008): As reference, a dilution series of epoetin $\beta$ (provided in the kit) ranging from 3 to $1,000 \mathrm{ng}^{-1}$ was measured by the MAIIA method; the obtained standard curve was fitted with a four-parameter logistic routine and from this the EPO concentrations in the urine samples were calculated (Lönnberg et al. 2012a).

The glycoform heterogeneity of the samples was analyzed by an EPO WGA MAIIA kit (MAIIA Diagnostics, Uppsala, Sweden) that previously have been used for detection of recombinant EPO in humans and horses (Lönnberg et al. 2012b; Lönnberg and Lundby 2013; Mørkeberg et al. 2013). In the present study we included umbilical cord (UC) plasma, which is known to contain mainly liver-derived EPO (Dame et al. 1998; Ohls 2002), as positive control for non-renal-derived EPO. For detailed description of the procedure refer to Lönnberg et al. (2012a). In brief, EPO from six UC plasma samples $(2 \mathrm{ml})$ and from the urine samples $(20 \mathrm{ml})$ obtained at $\mathrm{SL}$, HA1, HA3 and HA26 were purified on single-use antiEPO columns (EPO Purification Kit, MAIIA Diagnostics, Uppsala, Sweden) according to the directions of use. The average purification efficiency for the urine samples was $65 \pm 10 \%$.

The EPO WGA MAIIA isoform distribution kit is based on affinity chromatography - with immobilized lectins [wheat germ agglutinin (WGA)] interacting with the glycosylated EPO forms and $\mathrm{N}$-acetylglucosamine (Glc-NAc) used as competing sugar-in combination with lateral flow immunoassay. We established the optimal Glc-NAc concentration to be used in the elution buffer low by running pilot experiments at four different low Glc-NAc 
concentrations $(5,1015$, and $20 \mathrm{mM})$ and one high GlcNAc concentration $(300 \mathrm{mM})$ on samples containing EPO purified from UC and urine. Epoetin $\beta$ provided in the kit was included in all experiments and was used as reference (Lönnberg et al. 2012a). For the final determination of EPO glycoform distribution in the samples, 5 and $300 \mathrm{mM}$ of Glc-NAc were used in the elution buffers low and high, respectively. All samples were run in duplicates and under standardized conditions (e.g. temperature, humidity, using the same scanner and reagent lot number). The percent migrated isoform (PMI) values were calculated as the percent of EPO released by the elution buffer low with respect to the total EPO concentration (obtained by elution buffer high).

\section{Results and discussion}

Umbilical cord EPO and circulating EPO (urine and plasma) from healthy subjects gave different PMI values at the lower concentrations of Glc-NAc (Fig. 1), verifying the difference in glycosylation patterns (EPO glycoforms) depending on the origin of synthesis.

As expected (Berglund et al. 2002; Robach et al. 2007; Siebenmann et al. 2012) a peak $(p<0.05)$ in urine $(2.3 \pm 0.5$-fold $)$ and plasma $(3.3 \pm 0.5$-fold $)$ EPO was observed on HA1 and although reduced from that point remained elevated at HA26 for plasma by $1.5 \pm 0.2$-fold. One week after return to sea level also the plasma EPO concentrations had returned to SL values (Fig. 2).

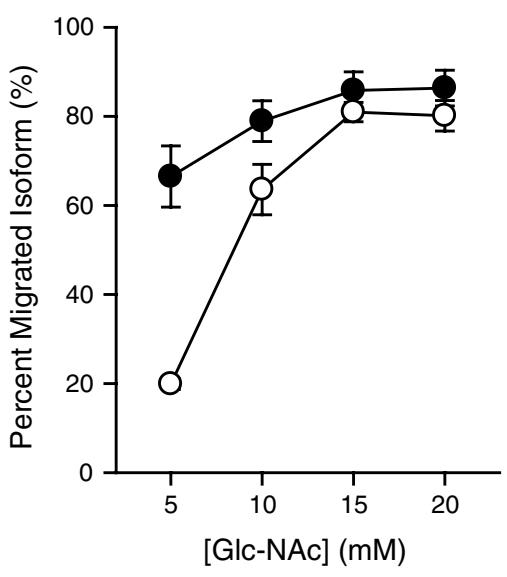

Fig. 1 The percent migrated isoform (PMI) values for umbilical cord EPO (closed circles) and circulating EPO from adults (open circles) when using different Glc-NAc concentrations in the elution buffer low. At the low $(5 \mathrm{mM})$ Glc-NAc concentration, the difference in PMI between the two EPO glycoforms is greatest and due to differences in glycolation in the two populations of EPO. Values are mean $\pm \mathrm{SEM}$, $n=6$ for $\mathrm{UC}, n=3$ for adults

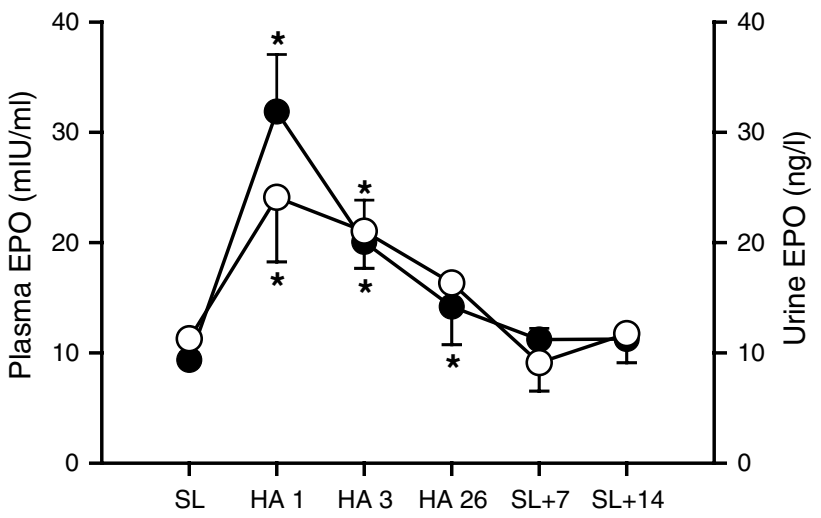

Fig. 2 Plasma (open circles) and urine (filled circles) EPO concentrations ( $\mathrm{mlU} \mathrm{ml}^{-1}$ and $\mathrm{ng}^{-1}$, respectively) in seven volunteers studied at sea level (SL) and after 1 (HA1), 3 (HA3) and 26 (HA26) days during exposure to $3,454 \mathrm{~m}$ altitude, and again after $7(\mathrm{SL}+7)$ and $14(\mathrm{SL}+14)$ days upon return to sea level. ${ }^{*} P<0.05$ as compared to SL. Values are mean \pm SEM

The EPO glycoform heterogeneity, expressed as percent migrated isoforms (PMI) (Lönnberg et al. 2012a) in the urine samples collected at altitude, did not differ from values at SL, but were markedly lower $(p<0.05)$ than the mean PMI for the umbilical cord samples (Fig. 3). Samples containing different EPO glycoforms (e.g. recombinant and endogenous EPO) have PMI values that are intermittent of the "pure glycoforms" (Lönnberg et al. 2012a, b, 2008; Lönnberg and Lundby 2013) and therefore a potential contribution of non-renal-derived EPO to the circulating EPO

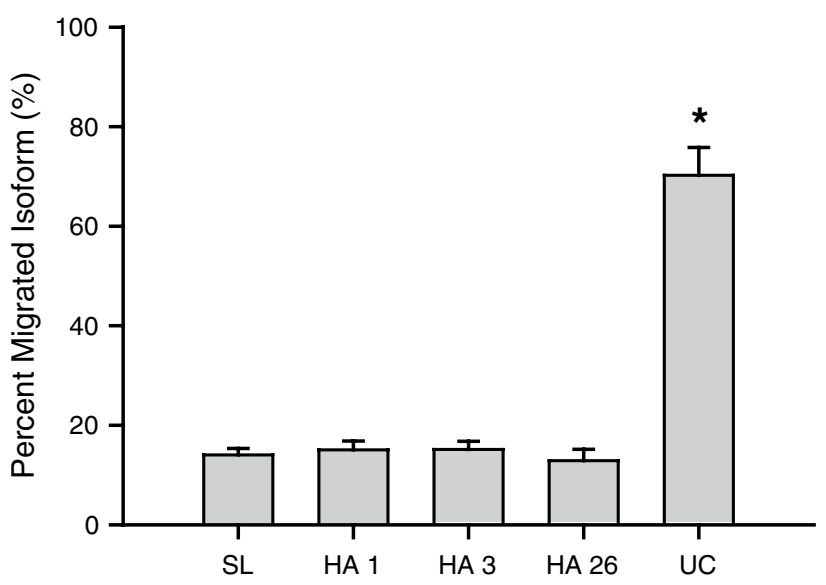

Fig. 3 EPO glycoform heterogeneity in samples obtained before and during acclimatization to high altitude. The PMI values are directly related to the glycoform composition of EPO in a given sample. Hence, for the HA samples an increase in PMI value from SL towards UC would be a consequence of a sample containing both renal and hepatic EPO. Abbreviations as for Fig. 1. Umbilical cord (UC) samples are here shown to have marked higher PMI values. $* P<0.05$ as compared to the samples obtained in the adult volunteers. Values are mean \pm SEM 
should have altered the PMI values when comparing SL to HA samples. Since this was not the case in the present study, we demonstrate in healthy humans exposed to highaltitude $(3,454 \mathrm{~m})$ hypoxia that the predominant source for the rise in plasma EPO is the kidney. Although we did not include a control for CNS-derived EPO in the present study (currently unavailable), it has been shown that brainderived EPO is less glycosylated than renal-derived EPO (Masuda et al. 1994), and hence an increase in PMI would be expected if more EPO was to be derived from the brain. Our findings are in line with previous studies on dogs, demonstrating that when exposed to $10 \%$ hypoxia, renal venous EPO content was $63 \%$ higher than arterial EPO content (Abbrecht and Malvin 1966). Although this does not exclude a contribution from other cells, the findings suggest a massive contribution of the kidneys to the circulating EPO response to hypoxia. When Bernhardt et al. (2010) administrated a prolyl hydroxylase inhibitor, which stabilizes HIF expression, kidney transplant patients demonstrated no increase in circulating EPO whereas this was the case in healthy volunteers. Thus, also from a biochemical perspective it seems clear that the kidneys are indeed the predominant organs responsible for the synthesis of circulating EPO when stimulated by HIF, as expected at high altitude. Our study demonstrates the differences in EPO glycoform distribution in neonatal umbilical cord samples as compared to adults, and thereby extends previous tissue mRNA work (Dame et al. 1998; Ohls 2002) suggesting liver cells to be the main site for EPO synthesis during gestation. Thus, although the human liver in the neonatal state has an important role in the synthesis of EPO and although astrocyte-derived EPO may account for up to $50 \%$ of the erythropoietic response in mice when exposed to hypoxia, this does not seem to be relevant for the circulating EPO levels in healthy adult humans when exposed to continuous hypoxia.

Conflict of interest The authors declare not to have any conflict of interest with regard to the study.

\section{References}

Abbrecht PH, Malvin RL (1966) Renal production of erythropoietin in the dog. Am J Physiol 210:237-242

Berglund B, Gennser M, ÖRnhagen H, ÖStberg C, Wide L (2002) Erythropoietin concentrations during 10 days of normobaric hypoxia under controlled environmental circumstances. Acta Physiol Scand 174:225-229

Bernaudin M, Bellail A, Marti HH, Yvon A, Vivien D, Duchatelle I, Mackenzie ET, Petit E (2000) Neurons and astrocytes express EPO mRNA: oxygen-sensing mechanisms that involve the redoxstate of the brain. Glia 30:271-278

Bernhardt WM, Wiesener MS, Scigalla P, Chou J, Schmieder RE, Günzler V, Eckardt K-U (2010) Inhibition of prolyl hydroxylases increases erythropoietin production in ESRD. J Am Soc Nephrol 21:2151-2156

Dame C, Fahnenstich H, Freitag P, Hofmann D, Abdul-Nour T, Bartmann P, Fandrey J (1998) Erythropoietin mRNA expression in human fetal and neonatal tissue. Blood 92:3218-3225

Fried W (1972) The Liver as a source of extrarenal erythropoietin production. Blood 40:671-677

Haase VH (2010) Hypoxic regulation of erythropoiesis and iron metabolism. Am J Physiol Renal Physiol 299:F1-F13

Jelkmann W (1992) Erythropoietin: structure, control of production, and function. Physiol Rev 72:449-489

Kapitsinou PP, Liu Q, Unger TL, Rha J, Davidoff O, Keith B, Epstein JA, Moores SL, Erickson-Miller CL, Haase VH (2010) Hepatic HIF-2 regulates erythropoietic responses to hypoxia in renal anemia. Blood 116:3039-3048

Lönnberg M, Lundby C (2013) Detection of EPO injections using a rapid lateral flow isoform test. Anal Bioanal Chem. doi:10.1007/ s00216-013-6997-8

Lönnberg M, Drevin M, Carlsson J (2008) Ultra-sensitive immunochromatographic assay for quantitative determination of erythropoietin. J Immunol Methods 339:236-244

Lönnberg M, Andrén M, Birgegård G, Drevin M, Garle M, Carlsson J (2012a) Rapid detection of erythropoiesis-stimulating agents in urine and serum. Anal Biochem 420:101-114

Lönnberg M, Bondesson U, Cormant F, Garcia P, Bonnaire Y, Carlsson J, Popot M-A, Rollborn N, Råsbo K, Bailly-Chouriberry L (2012b) Detection of recombinant human EPO administered to horses using MAIIA lateral flow isoform test. Anal Bioanal Chem 403:1619-1628

Lönnberg M, Garle M, Lönnberg L, Birgegård G (2013) Patients with anaemia can shift from kidney to liver production of erythropoietin as shown by glycoform analysis. J Pharm Biomed Anal 81-82:187-192

Lundby C, Thomsen JJ, Boushel R, Koskolou M, Warberg J, Calbet JAL, Robach P (2007) Erythropoietin treatment elevates haemoglobin concentration by increasing red cell volume and depressing plasma volume. J Physiol 578:309-314

Masuda S, Okano M, Yamagishi K, Nagao M, Ueda M, Sasaki R (1994) A novel site of erythropoietin production. Oxygendependent production in cultured rat astrocytes. J Biol Chem 269:19488-19493

Minamishima YA, Kaelin WG (2010) Reactivation of hepatic EPO synthesis in mice after PHD loss. Science 329:407

Mirand EA, Murphy GP, Steeves RA, Weber HW, RF P (1968) Extrarenal production of erythropoietin in man. Acta Hemaat (Basel) 39:359

Mørkeberg J, Sharpe K, Karstoft K, Ashenden MJ (2013) Detection of microdoses of rhEPO with the MAIIA test. Scand J Med Sci Sports. doi:10.1111/sms.12049

Ohls RK (2002) Erythropoietin and hypoxia inducible factor-1 expression in the mid-trimester human fetus. Acta Paediatr Suppl 91:27-30

Olsen NV, Aachmann-Andersen NJ, Oturai P, Andersen TM, Rasmussen AB, Hulston C, Holstein-Rathlou N-H, Robach P, Lundby C (2011) Recombinant human erythropoietin in humans downregulates proximal renal tubular reabsorption and causes a fall in glomerular filtration rate. J Physiol 15:1273-1281

Rasmussen P, Nordsborg N, Taudorf S, Sørensen H, Berg RMG, Jacobs RA, Bailey DM, Olsen NV, Secher NH, Møller K, Lundby C (2012) Brain and skin do not contribute to the systemic rise in erythropoietin during acute hypoxia in humans. FASEB J 26:1831-1834

Robach P, Cairo G, Gelfi C, Bernuzzi F, Pilegaard H, Vigano A, Santambrogio P, Cerretelli P, Calbet JAL, Moutereau S, Lundby C (2007) Strong iron demand during hypoxia-induced 
erythropoiesis is associated with down-regulation of ironrelated proteins and myoglobin in human skeletal muscle. Blood 109:4724-4731

Siebenmann C, Robach P, Jacobs RA, Rasmussen P, Nordsborg N, Diaz V, Christ A, Olsen NV, Maggiorini M, Lundby C (2012) "Live high-train low" using normobaric hypoxia: a doubleblinded, placebo-controlled study. J Appl Physiol 112:106-117
Weidemann A, Kerdiles YM, Knaup KX, Rafie CA, Boutin AT, Stockmann C, Takeda N, Scadeng M, Shih AY, Haase VH, Simon MC, Kleinfeld D, Johnson RS (2009) The glial cell response is an essential component of hypoxia-induced erythropoiesis in mice. J Clin Invest 119:3373-3383

Wide L, Bengtsson C (1990) Molecular charge heterogeneity of human serum erythropoietin. Br J Haematol 76:121-127 